\title{
Caloric restriction or resveratrol supplementation and ageing in a non-human primate: first-year outcome of the RESTRIKAL study in Microcebus murinus
}

\author{
Alexandre Dal-Pan • Jérémy Terrien • Fabien Pifferi • Roger Botalla • \\ Isabelle Hardy • Julia Marchal • Alexandre Zahariev • Isabelle Chery • \\ Philippe Zizzari • Martine Perret • Jean Luc Picq • Jacques Epelbaum • \\ Stéphane Blanc $\cdot$ Fabienne Aujard
}

Received: 27 January 2010 / Accepted: 19 May 2010 / Published online: 9 June 2010

C The Author(s) 2010. This article is published with open access at Springerlink.com

\begin{abstract}
A life-long follow-up of physiological and behavioural functions was initiated in 38-month-old mouse lemurs (Microcebus murinus) to test whether caloric restriction (CR) or a potential mimetic compound, resveratrol (RSV), can delay the ageing process and the onset of age-related diseases. Based on their potential survival of 12 years, mouse lemurs were assigned to three different groups: a control (CTL) group fed ad libitum, a CR group fed $70 \%$ of the CTL caloric intake and a RSV group $\left(200 \mathrm{mg} / \mathrm{kg}\right.$.day $\left.{ }^{-1}\right)$ fed ad libitum. Since this prosimian primate exhibits a marked annual rhythm in body mass gain during
\end{abstract}

A. Dal-Pan · J. Terrien · F. Pifferi $\cdot$ R. Botalla $\cdot$ I. Hardy $\cdot$ J. Marchal $\cdot \mathrm{I}$. Chery $\cdot$ M. Perret $\cdot$ F. Aujard $(\bowtie)$

Mécanismes Adaptatifs et Evolution,

UMR 7179 Centre National de la Recherche Scientifique,

Muséum National d'Histoire Naturelle,

1 avenue du petit château, 91800 Brunoy, France

e-mail: aujard@mnhn.fr

P. Zizzari · J. Epelbaum

Centre de Psychiatrie et Neuroscience, UMR 894 Inserm,

Faculté de Médecine, Université Paris Descartes,

2 ter rue d'Alésia, 75014 Paris, France

\section{J. L. Picq}

Laboratoire de Psychopathologie et Neuropsychologie,

UFR Psychologie, Université Paris 08,

2 Rue Liberté, 93526 St Denis, France

A. Zahariev $\cdot$ I. Chery $\cdot$ S. Blanc

Institut Pluridisciplinaire Hubert Curien, UMR 7178 CNRS

Université Louis Pasteur,

23 rue Becquerel, 67087 Strasbourg, France winter, animals were tested throughout the year to assess body composition, daily energy expenditure (DEE), resting metabolic rate (RMR), physical activity and hormonal levels. After 1 year, all mouse lemurs seemed in good health. CR animals showed a significantly decreased body mass compared with the other groups during long day period only. CR or RSV treatments did not affect body composition. CR induced a decrease in DEE without changes in RMR, whereas RSV induced a concomitant increase in DEE and RMR without any obvious modification of locomotor activity in both groups. Hormonal levels remained similar in each group. In summary, after 1 year of treatment CR and RSV induced differential metabolic responses but animals successfully acclimated to their imposed diets. The RESTRIKAL study can now be safely undertaken on a long-term basis to determine whether ageassociated alterations in mouse lemurs are delayed with $\mathrm{CR}$ and if RSV can mimic these effects.

Keywords Ageing · Food restriction ·

Resveratrol - Energy balance · Biomarkers .

Doubly labelled water method

\section{Introduction}

The main causes of mortality in western countries are chronic age-associated diseases such as cardiovascular diseases, cancers, type 2 diabetes, osteoporosis and kidney diseases. These diseases have a genetic back- 
ground but environmental factors such as nutrition play a key role (Mokdad et al. 2004). Since the pioneering study of McCay et al. (1935), we know that caloric restriction (CR) without malnutrition can delay the onset of such age-associated pathologies, delay ageing and increase lifespan in rodents. Observational data suggest that the relationship between longevity, energy balance and caloric intake could exist in humans but further investigations are needed.

Several hypotheses have been proposed for the biological mechanism underlying the life-extending and anti-ageing actions of CR, such as slowing growth, reducing body fat, altering apoptosis, decreasing body temperature and increasing physical activity, attenuating oxidative damage, reducing glycemia and insulinemia and modifying immune function (Campbell and Richardson 1988; Gredilla et al. 2001; Gardner 2005). It is likely that all these and others actions might indeed play a role and a unifying hypothesis was needed. The concept of hormesis might well provide such a hypothesis. This refers to phenomena in which the response of an organism to a chemical or physical agent is qualitatively different when the agent is of high intensity than when it is of low intensity (Rattan 2004). A $30 \%$ CR that delays the ageing processes is a low intensity stressor, which enhances the ability of rats, mice and monkeys of all ages to cope with intense stressors (Masoro 2006). The pathway by which $\mathrm{CR}$ enhances protective and repair processes has not yet been well elucidated. Recently, a mechanism was proposed for CR-induced effects in yeast (Saccharomyces cerevisiae). Lin et al. (2000) demonstrated that the functional Sir2 gene is required for $\mathrm{CR}$ to increase replicative longevity in that species. More recently, an increasing amount of data has suggested that silent mating-type information regulation 2 homologous 1 (SIRT1), one of the seven mammalian orthologues of the yeast Sir2, regulates cell survival to a number of stressors and might be central to the effects of CR (Cohen et al. 2004; Picard et al. 2004; Rodgers et al. 2005; Bordone and Guarente 2005; Baur 2010).

Until the late 1980s, CR had not been tested in any animal model living longer than 4 years. Since then, studies in non-human primates, including rhesus and squirrel monkeys, have been in progress at the National Institute of Ageing (NIA) and the University of Wisconsin (UW) (Ingram et al. 1990; Lane et al. 1992; Kemnitz et al. 1993). The proportions of both rhesus and squirrel monkeys already dead in 2002 in the CR cohorts were about half of the controls (Lane et al. 2002). The most recent result from the UW primate study has indicated that adult-onset mild CR delays the onset of age-associated pathologies and promotes survival in rhesus monkeys (Colman et al. 2009) but this study has not yet shown any effect of CR on the maximum life expectancy of primates. Recently, a similar study was initiated on human subjects. Results at 6 months of $\mathrm{CR}$ are consistent to what has been observed in monkeys and rodents in terms of lower metabolic rate, body temperature and insulin and reduced DNA damage (Heilbronn et al. 2006).

Further studies are needed to test the validity of the CR paradigm in non-human primates to delineate the still debated mechanisms by which CR extends lifespan and ultimately test the molecules or interventions that will mimic the effects of CR and be relevant to humans. The present study "RESTRIKAL" aims to investigate the long-term effects of CR or supplementation with a mimetic compound (resveratrol; RSV) on the ageing process and lifespan of a non-human primate and highlight similar action pathways in both treatments. In that respect, the main originality of this study lies in the animal model, the grey mouse lemur (Microcebus murinus) whose size (60-110 g) and life expectancy (8-10 years) will allow obtaining longevity data in 5 years only. M. murinus is a nocturnal prosimian primate originating from Madagascar. The grey mouse lemur presents special characteristics that make it a unique model to investigate energy regulation and ageing processes. Firstly, it displays a strong seasonal rhythm linked to photoperiod that is associated with natural and massive winter obesity i.e. an important increase in body mass due to fat storage in only a few weeks (Génin and Perret 2000). Secondly, grey mouse lemurs exhibit very marked daily rhythms with periods of heterothermia during their diurnal resting phase (Perret and Aujard 2001). These phases of daily heterothermia, very rare in primates, are an efficient mechanism of energy saving in small mammals (Terrien et al. 2009a) and thereby a good response index to energy stresses. It is also a unique model to assess the importance of biological rhythms on the processes of ageing and longevity. For example, a weakened and fragmented locomotor activity rhythm during normal ageing has been demonstrated in this primate (Cayetanot et al. 2005). The longevity of this primate is adequate for performing longitudinal studies, 
and several biomarkers of ageing have already been validated in the mouse lemur colony, in particular decrease in sexual and aggressive behaviours (Aujard and Perret 1998; Nemoz-Bertholet et al. 2004), decrease in sexual hormones (Aujard and Perret 1998), melatonin (Aujard et al. 2001), DHEA-S (Perret and Aujard 2005) and insulin-like growth factor-1 (IGF-1) (Aujard et al. 2010), cognitive impairments (Picq 2007) and MRI-evaluated cerebral atrophy (Dhenain et al. 2003; Kraska et al. 2009). Moreover, it has recently been demonstrated that the energy balance of aged mouse lemurs is impaired in response to cold exposure (Terrien et al. 2009b). The first aim of this study is to determine whether CR can modify the physiological processes in the grey mouse lemur that lead to a delay in age-related diseases and an increase in lifespan.

The second aim of this study is to determine whether $\mathrm{RSV}$, a natural polyphenolic compound that activates proteins implicated in energy metabolism homeostasis, could be used as a mimetic compound of CR. Indeed, CR will be very difficult to implement in humans because of social and practical constraints. In the past 5 years, numerous studies have focused on the development of "CR mimetic" compounds that would minimise many age-related diseases in humans without a reduction in caloric intake (Weindruch et al. 2001; Chen and Guarente 2007; Ingram et al. 2007; Wakeling et al. 2009). Among them, RSV seems to be a promising molecule (Howitz et al. 2003; Borra et al. 2005; Lagouge et al. 2006; Allard et al. 2009; Anderson and Prolla 2009). Trans-RSV, the most active form of $\mathrm{RSV}$, has been the subject of many in vitro, ex vivo and in vivo studies to test its various and promising antiinflammatory (Donnelly et al. 2004), anti-oxidant (Iannelli et al. 2007), anti-cancer (Baur et al. 2006), metabolic and cardiovascular (Shanmuganayagam et al. 2007) properties.

Although RSV effects share many metabolic similarities with CR (Barger et al. 2008) and although it seems to be a promising molecule to delay the incidence of age-associated chronic diseases (Athar et al. 2007), its metabolic effects in primates are still unknown. Indeed, relatively low concentrations can extend yeast, worm and Drosophila lifespan in a Sir2-dependent manner by mimicking CR (Wood et al. 2004). More interestingly, RSV can activate SIRT1, the most studied mammalian orthologue of Sir2, in humans (Borra et al. 2005). Most recently, several studies have also demonstrated RSV can stimulate AMPK activity in mice (Dasgupta and Milbrandt 2007; Canto et al. 2009). These results highlight that RSV could play an important part in energy regulation processes. RSV treatment also reduces the signs of ageing in mice but does not increase the longevity of ad libitum-fed animals when started at midlife (Pearson et al. 2008). However, non-human primates and humans present metabolic responses to a long-term $\mathrm{CR}$ and mimetic compound that might differ slightly from what was repeatedly observed in rodents and other lower organisms (Heilbronn et al. 2006; Colman et al. 2009; Witte et al. 2009). For example, CR in mice down-regulates genes involved in oxidative stress and reduces oxidative damage, lipid peroxidation and protein carbonyls (Sohal et al. 1994; Dubey et al. 1996; Lee et al. 1999; de Oliveira et al. 2003). In non-human primates, genes involved in protection against oxidative stress are not altered by CR, although protein carbonylation is reduced (Zainal et al. 2000). More data on primates are needed. Thus, the third goal of the study is to define whether $\mathrm{CR}$ and RSV act through similar pathways by stimulating sirtuins in the mouse lemur. This point will be developed in future years of the study.

Since the beginning of the RESTRIKAL study, a battery of tests has been performed on adult grey mouse lemurs at regular intervals until their natural death to assess the impact of both treatments on energy metabolism modification and the ageing process. These tests were selected to assess parameters changing with chronological ageing. They are minimally invasive and appropriate for a longitudinal study. Several indices of energy balance were measured such as body mass gain, food intake, body composition, resting metabolic rate (RMR) and physical activity. Concerning endocrine systems, IGF-1 levels were measured because this hormone is a modulator of energy balance and an ageing marker that declines with time (Aujard et al. 2010). Indeed, genetic alterations in the human IGF-1 receptor that result in an altered IGF signalling pathway seem to be linked to human longevity, suggesting a role of this pathway in the modulation of human lifespan (Suh et al. 2008). Testosterone levels are also measured to highlight possible effects on sexual behaviour and, notably, test if the balance between reproduction cost and survival of grey mouse lemurs is modified. The first-year outcome of this longitudinal follow-up 
demonstrates the validity of CR and RSV interventions for assessing whether they can delay ageing in a non-human primate. We expect that the present study will provide novel insights into the biology of ageing by testing the effect of CR or RSV treatment on a non-human primate model. We expect that CR will increase lifespan in the grey mouse lemurs and decrease markers of several chronic diseases. Lastly, we expect that RSV stimulation of the sirtuin pathway will mimic the effect of CR. In the long run, such a study might allow us to develop nutritional strategies to delay the effect of ageing.

\section{Experimental procedures}

Animals and animal care

The 42 male grey mouse lemurs (M. murinus, Cheirogaleidae, primates) used in this study were born in the laboratory breeding colony at Brunoy, France (agreement A91-114-1) from stock originally caught more than 40 years ago on the southwest coast of Madagascar. All animals were included in a single cohort at the age of $38 \pm 1$ months, which is considered an adult age in this species. The project began at the onset of the winter-like season in the lab. The general conditions of captivity were maintained with respect to ambient temperature $\left(25^{\circ} \mathrm{C}\right)$ and relative humidity $(55 \%)$. The grey mouse lemur is a nocturnal primate that shows high levels of locomotor activity and normothermic body temperature during the night. Just before the onset of the light phase, it enters a torpid state during which it decreases its body temperature and metabolic rate until 4 to $6 \mathrm{~h}$ after the beginning of the day when its body temperature returns to normothermic values. The mouse lemur exhibits photoperiod-dependent seasonal variations in most of its physiological functions. Another interesting particularity of this species is its body mass gain during winter. Indeed, at the beginning of winter the body mass of the grey mouse lemur increases by approximately $50 \%$ to $70 \%$ and only returns to basal levels in the summer. In the breeding colony, animals are exposed to an artificial photoperiodic regimen consisting of six months of summer-like long day length (14:10 h light-darkness, LD) and 6 months of winter-like short day length (10:14 h light-darkness, SD). These photoperiodic regimens are sufficiently discriminating to induce radically different physiologi- cal and behavioural responses, as observed in nature in Madagascar. The change of photoperiod occurred abruptly without any significant disturbance for the animals. To minimise social influences during the different experiments, animals were housed individually in $1 \mathrm{~m}^{3}$ cages, provided with a nest and supports and separated from each other by metallic partitions. Animals were weighed once a week to monitor body mass variations. All experiments were performed in accordance with the Principles of Laboratory Animal Care (National Institutes of Health publication 86-23, revised 1985) and French national laws.

\section{Dietary interventions}

Animals were fed with the same standard diet used in the laboratory breeding colony and in recent publications using the same animal model (Génin and Perret 2003; Giroud et al. 2008b; Giroud et al. 2010). They were fed with fresh fruit (banana and apple) and a daily mixture made up of cereals, milk and egg. This diet is composed of $61 \%$ carbohydrates, $23 \%$ proteins and $16 \%$ lipids. Water was always given ad libitum.

After a 2-week habituation phase, animals were randomised to the following groups. An ad libitum control (CTL) group of 14 animals was fed with the standard diet. The daily amount of food given to the animals ( $15 \mathrm{~g}$ of mixture and $6 \mathrm{~g}$ of fresh fruit per day, equivalent to $105 \mathrm{~kJ} /$ day on average) was estimated from preliminary internal studies of the Brunoy laboratory over a year of measuring spontaneous food intake in isolated control adult animals (unpublished data). During the first 2 weeks of the SD period, animals remained undisturbed and more food (169 kJ/ day) was given to allow annual fattening. Then, the amount was progressively decreased $(128 \mathrm{~kJ} /$ day in the third week, $116 \mathrm{~kJ} /$ day in the fourth week) until the fifth week when the amount of food was fixed for the rest of the year $(102 \mathrm{~kJ} /$ day $)$. A CR group of 14 animals was fed the same diet but received $30 \%$ less than the CTL group, which corresponded to an average of $71 \mathrm{~kJ}$ per day (i.e. $10 \mathrm{~g}$ of mixture and $4 \mathrm{~g}$ of fresh fruit per day). This restriction was based on several studies on different species (Lane et al. 2000; Blanc et al. 2003). It was applied throughout the year, except during the critical period of fattening. During the first 3 weeks of the SD period, CR animals received the same amount of 
food as the CTL group to allow them to fatten normally and, after these first 3 weeks, the $30 \%$ caloric restriction applied was the same during SD and LD periods. Finally, a third group (RSV group) of 14 animals was fed with the same quantity of food as CTL but supplemented with $200 \mathrm{mg}$ of RSV per kilogram bodyweight per day (Sequoia Research Products, UK). This dosage was selected from the literature from studies in rodents, and was intermediate between the $40 \mathrm{mg} / \mathrm{kg} . \mathrm{d}^{-1}$ of Baur et al. (2006) and the $400 \mathrm{mg} / \mathrm{kg} . \mathrm{d}^{-1}$ of Lagouge et al. (2006). To know exactly the quantity of food really ingested by the animals, daily leftovers were measured and corrected for water evaporation.

Daily energy expenditure, body composition and water turnover

Measurements were performed twice a year on 12 of the 14 animals in each group in the first weeks following each dietary shift (SD1, LD1) (Fig. 1). Daily energy expenditure (DEE) was measured over a 3-day period using the doubly labelled water (DLW) method (Blanc et al. 2000). Animals were weighed before the experiment to determine the dose of DLW to be injected. After urine collection for the determination of basal enrichments, animals were injected in the intraperitoneal cavity with $2.3 \mathrm{~g} / \mathrm{kg}$ of a pre-mixed solution composed of $0.55 \mathrm{~g} / \mathrm{kg} \mathrm{H}{ }_{2}{ }^{18} \mathrm{O}$ (Rotem Industries, Israel) and $0.15 \mathrm{~g} / \mathrm{kg}{ }^{2} \mathrm{H}_{2} \mathrm{O}$ (Cambridge Isotope Laboratories, Andover, MA, USA) diluted in
$10 \mathrm{~g}$ of $\mathrm{NaCl} 9 \%$ to maintain osmolarity. These quantities of isotopes ensured in vivo enrichments of deuterium in the order of $300 \mathrm{ppm}$ and 2,400 ppm for oxygen-18. Isotopic equilibration in total body water (TBW) was determined from a blood sample collected using a glass capillary at $1 \mathrm{~h}$ post-dose from the saphenous vein. Immediately after sampling, the capillary tubes were flame-sealed to prevent isotopic exchanges. The mouse lemur was then released into its cage and urine samples were collected in cryogenically stable tubes 24,48 and $72 \mathrm{~h}$ after blood sampling. Blood and urine samples were respectively stored at $5^{\circ} \mathrm{C}$ and $-20^{\circ} \mathrm{C}$ until analyses by isotope ratio mass spectrometry.

Water from serum and urine samples were extracted by cryo-distillation, as previously described (Gilbert et al. 2007). A $0.1 \mu \mathrm{L}$ of water was reduced to hydrogen and carbon monoxide by reduction on a glassy carbon reactor held at $1,400^{\circ} \mathrm{C}$ in an elemental analyser (Flash HT, Thermofisher, Germany). Hydrogen and carbon monoxide gases were separated by a gas-liquid chromatography column held at $104^{\circ} \mathrm{C}$ coupled to a continuous flow Delta-V isotope ratio mass spectrometer. Isotopic abundances of deuterium and 18-oxygen in hydrogen and carbon monoxide gases were measured in quintuplicate and repeated if SD exceeded $2 \%$ and $0.5 \%$, respectively. All enrichments were expressed as International Atomic Energy Agency standards. $\mathrm{CO}_{2}$ production was calculated according to the single pool equation of Speakman (Blanc et al. 2000): $\quad \mathrm{rCO}_{2}=(\mathrm{N} / 2.078) \times(\mathrm{ko}-\mathrm{kd})-0.0062 \times \mathrm{kd} \times \mathrm{N}$,

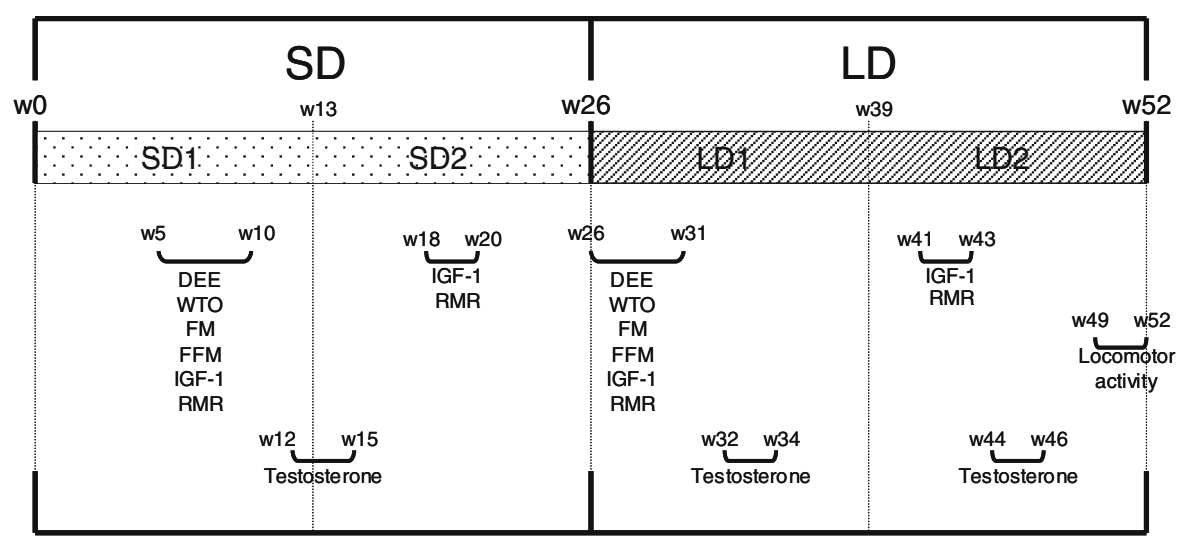

Fig. 1 Experimental schedule during the first year of the RESTRIKAL study. Daily energy expenditure $(D E E)$, water turnover $(W T O)$, fat mass $(F M)$ and fat-free mass $(F F M)$ were assessed twice a year. Measurement of insulin-like growth factor type $1(I G F-1)$ level and resting metabolic rate $(R M R)$ were performed four times a year. Testosterone level analysis was performed three times a year, once in SD and twice in long days $(L D)$ period. Locomotor activity was tested once a year at the end of the LD period during which the animals remain relatively active ( $w$ week) 
where $\mathrm{N}$ represents the average isotope dilution space of oxygen-18 calculated from Coward (1990) by the plateau method using the $1 \mathrm{~h}$ post-dose sample. ko and $\mathrm{kd}$ represent the isotope constant elimination rates calculated by linear regression of the natural logarithm of isotope enrichment as a function of elapsed time from day 1 samples. DEE was calculated by Weir's equation (Weir 1949) using a food quotient of 0.86 estimated from the animal's diet. TBW was measured from the dilution space of 18-oxygen after correction for exchange by the factor 1.007 (Racette et al. 1994). Fat-free mass (FFM) was calculated from TBW by assuming a hydration coefficient of $73.2 \%$, which was shown to be unchanged by chronic CR (Blanc et al. 2005). Fat mass (FM) was calculated as the difference of FFM from body mass. Water turnover was assessed by the multiplication of the average isotope dilution space of oxygen-18 (N) with the deuterium constant elimination rate $(\mathrm{kd})$ and corrected for isotope fractionation (Blanc et al. 2000). FFM and FM were expressed in g, TBW was expressed in \% and DEE was expressed in $\mathrm{kJ} /$ day.

\section{Resting metabolic rate}

Oxygen consumption was measured with a closed circuit respirometer. This protocol was applied four times per year, in the first and last third of each photoperiod (SD1, SD2, LD1 and LD2) (Fig. 1). All the animals were experimented with this procedure (13 CTL, 14 CR and 14 RSV). For this nocturnal species, RMR measurements on post-absorptive animals were performed during their daily resting period, 4-6 $\mathrm{h}$ after the beginning of the light period to avoid torpor metabolism. Animals were trained to nest in the respiratory chamber that consisted of an opaque chamber of 2.51 with a woven floor to absorb any urine. During the experiment, the respiratory chamber was placed in a cabinet at a controlled ambient temperature of $25.0 \pm 0.5^{\circ} \mathrm{C}$, a value within the thermoneutral zone defined for the mouse lemur (Aujard and Perret 1998). After a $20 \mathrm{~min}$ habituation phase under constant air-flow ventilation $\left(21 . \mathrm{min}^{-1}\right)$ drawn through the respirometry chamber from bottom to top; the chamber was closed for a $40 \mathrm{~min}$ period. $\mathrm{VO}_{2}$ consumed by the animal was calculated from initial and final concentrations of $\mathrm{O}_{2}$ in the chamber that were measured on dried gas using a Servomex 570 A paramagnetic gas analyser (accuracy $0.01 \% \mathrm{O}_{2}$ ). The analyser was routinely calibrated with $\mathrm{N}_{2}$ and atmospheric air. $\mathrm{O}_{2}$ consumption was expressed as $\mathrm{ml} \mathrm{O}_{2}$ $\mathrm{h}^{-1}$. $\mathrm{O}_{2}$ consumption was adjusted for the body weight of the animal (Blanc et al. 2003). Body temperatures were not measured before the experiment to avoid disturbance of the sleeping animal but males never entered deep torpor at an ambient temperature of $25^{\circ} \mathrm{C}$.

Spontaneous locomotor activity

Spontaneous locomotor activity was estimated once a year at the end of the LD period, during their breeding season, when the animals are more active (Aujard et al. 2007) (Fig. 1). For technical reasons, only five CTL, nine CR and seven RSV followed this protocol. Spontaneous locomotor activity was estimated using a device with presence and motion sensors adapted to the mouse lemur (homemade system developed in the laboratory). The apparatus was placed in an ambient temperature controlled room $\left(25^{\circ} \mathrm{C}\right)$. Animals were housed individually in a cage with a capacity of $1 \mathrm{~m}^{3}$ each provided with nest and supports. Each animal was placed in a totally closed wooden nest, except for both sides of the nest on which were placed eight presence sensors (Honeywell, transmitter: SEP8705003, receiver: SDP8405014) to know when the animal was in the nest. These presence sensors were continuously recording. Moreover, two motion sensors (Gardtec, Gardscan ' $M$ ' series infrared detectors) were placed in the corners of the cage to detect the spontaneous movements of the animal during its activity period. If the animal was in movement, the motion sensors recorded data every two seconds. Thus, data were expressed in arbitrary units (a.u.). Data were stored in a computerised system (developed in the laboratory). They were then computed to represent the time course of these movement patterns using a software filtering "Actocebe 3.0" developed in language G from National Instruments. Total movements were averaged at 5-min intervals for further analysis.

\section{Hormonal assays}

Blood collections were taken via the saphenous vein of the animals, without anaesthesia, at the end of their resting phase before the food allotment became available. Blood was collected in capillary tubes containing EDTA and immediately centrifuged 
(7,000 rpm at $4^{\circ} \mathrm{C}$ for $30 \mathrm{~min}$ ) after collection. One hundred microlitres was collected per sampling and represented less than $2 \%$ of the blood volume of the animal. Plasma was stored at $-80^{\circ} \mathrm{C}$.

Blood sampling for IGF-1 level analysis was performed four times a year, in the first and last third of each photoperiod (SD1, SD2, LD1 and LD2) (Fig. 1). IGF-1 level was measured for 11 animals by group, using an IGF-1 IRMA kit (Immunotech SA, Marseille Cedex, France). A dilution step was performed before the assay to dissociate IGF-1 from its binding proteins. The antibodies used in this immunoassay are highly specific for IGF-1 (extremely low cross-reactivity against insulin, pro-insulin, IGF-2 and growth hormone). The intra-assay coefficient of variation was $6.3 \%$ and inter-assay coefficient of variation was $6.8 \%$. Assay sensitivity was $2 \mathrm{ng} / \mathrm{ml}$. Values were expressed in $\mathrm{ng} / \mathrm{ml}$.

Blood sampling for testosterone level analysis was performed three times a year, in the middle of the SD period and twice during the LD period, which is the activity period of grey mouse lemur (SD, LD1 and LD2) (Fig. 1). Testosterone was analysed for $12 \mathrm{CTL}$, $11 \mathrm{CR}$ and $11 \mathrm{RSV}$. Testosterone was assayed using the testosterone ELISA kit DE1559 (Demeditec, Kiel, Germany), which measures the total testosterone in plasma (expressed in $\mathrm{ng} / \mathrm{ml}$ ). After two distinct periods of incubation of 60 and $15 \mathrm{~min}$ with the different reagents, the optical density was read with a spectrophotometer at $450 \mathrm{~nm}$ (Bio-Tek Instruments Inc., Winooski, USA). Assay sensitivity was $0.083 \mathrm{ng} / \mathrm{ml}$. The intra-assay coefficient of variation was $6.7 \%$ and inter-assay coefficient of variation was $9.7 \%$. Values were expressed in $\mathrm{ng} / \mathrm{ml}$.

Testis size variations of each animal, expressed as a scale in a.u., was assessed once a week by the same person to complete the testosterone level analysis by estimating visually their sexual status (if there was no testis, a score of zero was given, if the testis began to appear, a score of one and when the testis were well developed, a score of two).

Mortality data

Animals are followed until their spontaneous death. All animals that will die during the study undergo a complete autopsy by a veterinarian. Based on specific criteria (rapid body mass loss, anaemia, difficulty breathing), dying animals will be deeply anaesthe- tised. After autopsy will be completed, all organs will be harvested and kept for future analysis. Special attention will be give to the mouse lemur's brain to check it for Alzheimer-like pathology.

\section{Sample size}

For calculation, we chose the increase in the mean lifespan as the primary outcome. In the breeding colony of the Brunoy laboratory, analysis of survival from 254 male mouse lemurs allowed us to determine the mean lifespan (mean \pm SEM: $6.0 \pm 0.2$ years), the mean lifespan of the $10 \%$ longest living animals (10.0 \pm 0.2 years) and the observed maximal survival duration (12.0 years). Based on literature (Lin et al. 2000; Tissenbaum and Guarente 2001, Anderson et al. 2003; Howitz et al. 2003; Ingram et al. 2006; Valenzano et al. 2006), we expected that the mean lifespan of the restricted and the RSV-supplemented groups would increase by a minimum of $30 \%$. With this parameter, assuming a common standard deviation of $5 \%$ and a power analysis of $80 \%$, a sample size of 12 individuals per group was required. We chose to increase the groups size $(n=14)$ to compensate the effect of early hazardous deaths in reducing statistical powers of metabolic and behavioural variables measured throughout the time course of the study during the project. The actual total power will be recalculated a posteriori.

\section{Statistical analysis}

Because of the large amount of data gathered during this longitudinal study, an Access database was created to comprehensively analyse all the results. For technical and setup reasons, the number of animals used for each experiment varied, especially for the locomotor activity monitoring, which was planned after the beginning of the project. Moreover, one animal of the CTL group suffering from a urinary tract infection died during the first year of this study and was removed from the analysis. All values are expressed as mean \pm SEM. After checking for the normality of the distribution, ANOVA or repeated ANOVA for related samples was used to assert significant variations in all studied parameters. Data from average seasonal body mass plateaus and IGF-1 levels were log-transformed to obtain data with a normalised distribution. Adjustments of FFM, RMR 
and TEE for body size were performed by analysis of covariance with a fluctuating slope model. Comparisons were considered to differ significantly when $p<0.05$. All statistics were performed by SYSTAT for Windows (V9, SPSS Inc., USA).

\section{Results}

Seasonal variations in the weekly average percentage of spontaneous food ingested related to the amount of food given and seasonal variations in body mass are represented in Fig. 2. The percentage of calories ingested (CI) significantly varied throughout the year (Fig. 2a). In CTL animals, a spontaneous and progressive decrease in CI was observed during the $\mathrm{SD}$ period to reach a minimum of $75 \%(76 \mathrm{~kJ} /$ day $)$ in the last third of the SD period. CI was higher in LD with an average of $92 \%$ (90 kJ/day) in the second part of the LD period. CI always remained below $100 \%$ $(102 \mathrm{~kJ} /$ day), confirming that CTL animals were always fed ad libitum. RSV animals exhibited similar seasonal variations in CI compared with CTL, except at the beginning of LD. Indeed, CI increased rapidly in the RSV group after the shift to LD, whereas the increase was more progressive in the CTL group. CR lemurs demonstrated higher percentages of CI throughout the year compared with CTL and RSV lemurs. Seasonal variations were less marked, but a spontaneous decrease in CI during SD was still
Fig. 2 Effects of caloric restriction $(C R)$ or resveratrol supplementation $(R S V)$ on seasonal variations in percentage of calories ingested $(C I)(\mathbf{a})$, body mass gain (b) and body mass plateaus (c). Data of the comparison of mean body mass gain during the short days $(S D)$ and long days $(L D)$ plateaus were logtransformed. Plateaus were calculated from weeks 13 to 19 for the SD period and weeks 38 to 44 for the LD period. ANOVA results are reported on the right side of the graphs, for treatment $(T r)$, photoperiod $(P)$ or crossed effects $(C)$ on the percentage of $\mathrm{CI}$ and body mass changes during the first year of CR or RSV supplementation compared to control feeding (CTL) in SD and LD animals $(n=13$ for CTL group, $n=14$ for CR group, $n=14$ for RSV group). $p$ in bold means value is significant and $p$ in italic means value is not significant but shows a trend. Values are expressed as mean \pm SEM
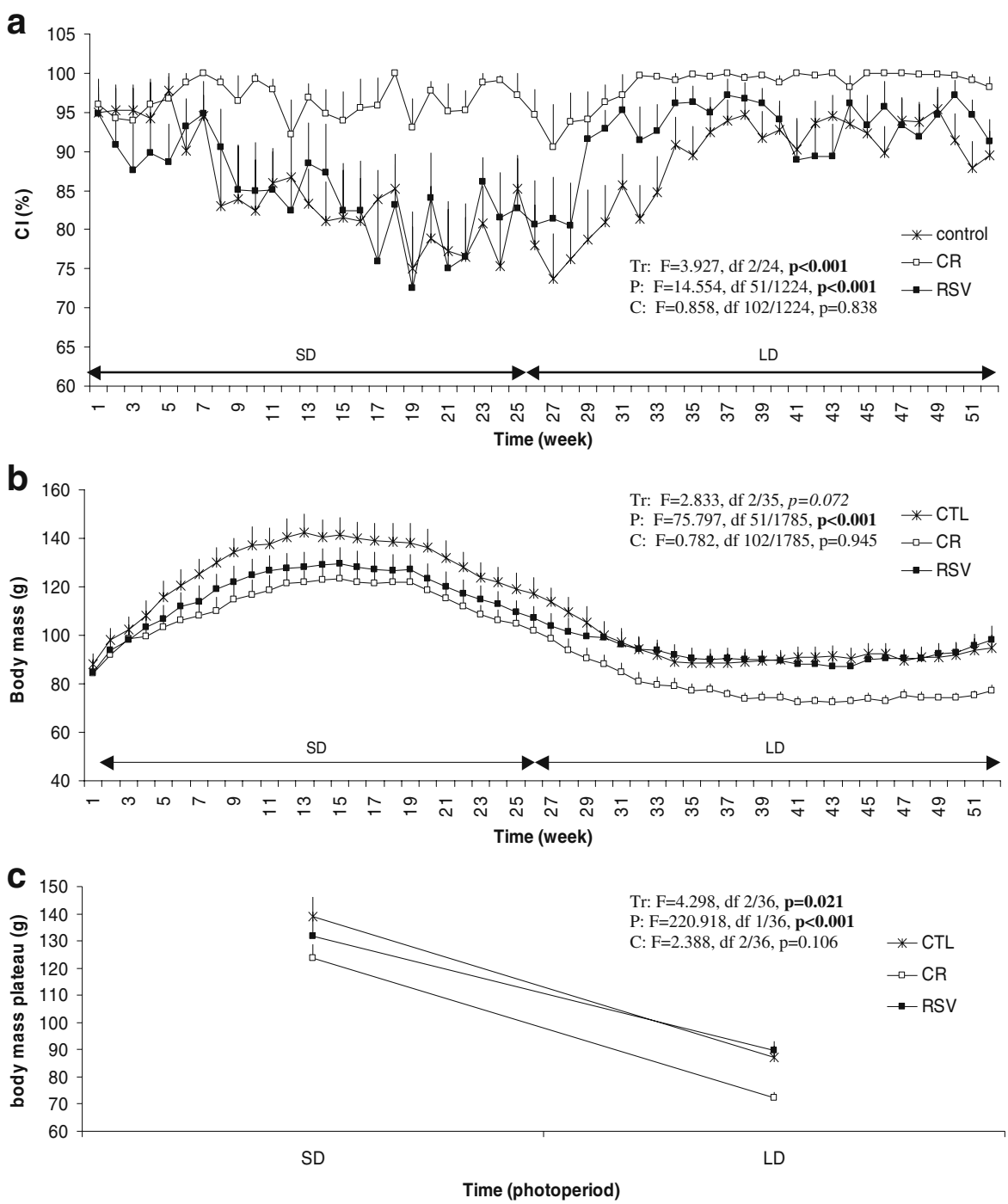
observed $(p=0.046)$. CR animals ingested an average $95 \%(68 \mathrm{~kJ} /$ day $)$ of their food portion during SD and $98 \%(70 \mathrm{~kJ} /$ day $)$ during LD. The percentage of restriction really applied throughout the year was less than $30 \%(19 \pm 1 \%$ in SD and $24 \pm 1 \%$ in LD).

As shown in Fig. 2b, the animals presented an initial average body mass of $90 \pm 5 \mathrm{~g}$. All animals fattened during the first 12 weeks of the SD period to reach a plateau of $131 \pm 8 \mathrm{~g}$ about $8-9$ weeks before decreasing their body mass until another plateau of $83 \pm 9 \mathrm{~g}$ in the middle of the LD period (Fig. $2 \mathrm{~b}, p<0.001$ ). Across the first year of the study, body mass did not significantly differ between the three groups even though a trend effect of treatment was observed $(p=0.072)$. However, when the data were split by seasons, CR animals presented a lower body mass compared with CTL and RSV groups during the second half of the LD period ( $74 \pm 2$ vs. $87 \pm 4$ and $90 \pm$ $3 \mathrm{~g}$, respectively, $p=0.021$, Fig. $2 \mathrm{c}$ ).

Analyses of body composition, DEE and water turnover following each new photoperiod are represented in Fig. 3. These parameters measured the short-term effect of treatment (within the second month following the first shift to SD) and the effect of 6 months of treatment (within the first month following the next shift to LD). Body mass at the time of these measures varied significantly according to season, with higher values in SD than in LD, but did not vary significantly according to treatment (Fig. 3a). There was no significant effect of time or treatment on FFM values $(75 \pm 2 \mathrm{~g}$ for CTL, $72 \pm 3 \mathrm{~g}$ for CR and $73 \pm 2 \mathrm{~g}$ for RSV in SD and $71 \pm 1 \mathrm{~g}$ for CTL, $68 \pm 2 \mathrm{~g}$ for $\mathrm{CR}$ and $76 \pm 2 \mathrm{~g}$ for RSV in LD, Fig. 3b). However, a crossed effect close to significance was observed, with a decrease in FFM in LD compared with SD for CTL and CR animals, whereas inversely RSV-treated lemurs increased their FFM in the LD season. By contrast, a clear effect of season was observed for FM values with higher levels of FM in SD than in LD, without any significant effect of treatment (Fig. 3c). TBW did not differ between the three groups whatever the photoperiod, but it varied similarly between SD and LD for each group $(46 \pm 1 \%$ in $\mathrm{SD}$ and $57 \pm 1 \%$ in LD) (Fig. 3d). Water turnover did not differ according to photoperiod or treatment but the cross effect was almost significant $(p=0.055)$. $\mathrm{CR}$ and RSV groups presented lower values in SD compared with the CTL group and maintained similar levels of water turnover in LD compared with SD, whereas CTL animals showed decreased water turnover rate in LD compared with SD (Fig. 3e). The evaluation of DEE revealed a significant effect of treatment with no global effect of season. CR animals exhibited lower values of DEE than CTL and RSV animals in both photoperiods, and RSV animals exhibited higher DEE values than the two other groups in LD only (Fig. 3f). These effects were maintained when DEE was adjusted to body mass (Fig. 3g).

RMR varied according to photoperiod and treatment (crossed effect: $F=2.450, d f 6 / 114, p=0.029)$ (Fig. 4). In CTL animals, RMR was higher in early SD and late LD. CR animals presented similar RMR values compared with the CTL group throughout the year $(p=1.000)$. By contrast, the RMR values of the RSV group significantly increased throughout the year $(p=$ 0.011). Significant differences appeared between the groups. In LD1, RMR was higher for the RSV group compared with CTL $(p=0.044)$. In LD2, this difference between RSV and CTL was even more pronounced $(p=0.003)$. During the late LD season, spontaneous daily locomotor activity was no different between the three groups of animals $(1,987 \pm 630$ a.u. for CTL, $2,644 \pm 457$ a.u. for $\mathrm{CR}$ and $1,379 \pm 338$ a.u. for RSV, $p=0.157$ ) (Fig. 5).

IGF-1 levels significantly varied according to photoperiod $(p<0.001)$, with lower values in early $\mathrm{SD}$ and late LD in all groups (Fig. 6). Despite a trend for a global treatment effect, IGF levels were not significantly different between the three groups whatever the photoperiod ( $p=0.078)$.

Highly significant differences in testis size (Fig. 7a) and testosterone levels (Fig. 7b) occurred between each photoperiod $(p<0.001)$ but treatment did not affect these parameters ( $p=0.726$ and $p=0.203$, respectively).

\section{Discussion}

The RESTRIKAL project aimed to compare for the first time the effects of a long-term $\mathrm{CR}$ or a mimetic compound supplementation on multiple ageing processes in a heterothermic primate. After 1 year, all mouse lemurs appeared in excellent health, suggesting no detrimental effect of both diets. Expected variations because of photoperiodic entrainment were present in all groups. Neither CR nor RSV supplementation affected photoperiodic variations in FFM, FM, TBW, water turnover, IGF-1 


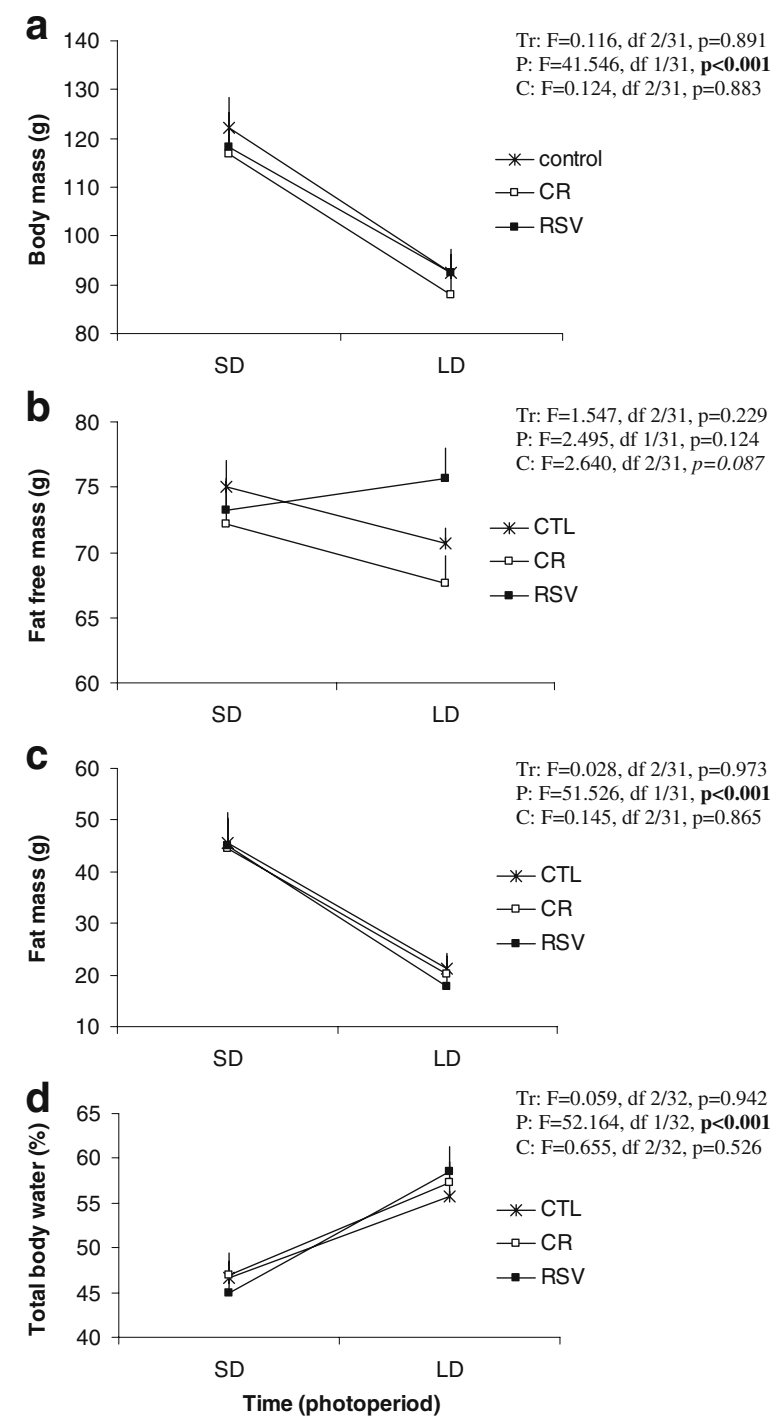

Fig. 3 Effects of photoperiod and treatment on body mass at the time of the experiment (a), fat-free mass (b), fat mass (c), total body water (d), water turnover (e), daily energy expenditure (f) and daily energy expenditure adjusted to body mass (g). ANOVA results are reported on the right side of the graphs, for treatment $(T r)$, photoperiod $(P)$ or crossed effects $(C)$ on body mass, fat-free mass, fat mass, total body water, water turnover and daily energy expenditure adjusted or not to body mass during the first year of caloric restriction $(C R)$ or

levels or testosterone levels. However, the evolution of FFM and water turnover in RSV-supplemented animals presented several differences compared with controls. Indeed, FFM and water turnover values in the RSV group varied in an opposite manner to the CTL group. Moreover, the RSV group exhibited higher values of DEE at the e
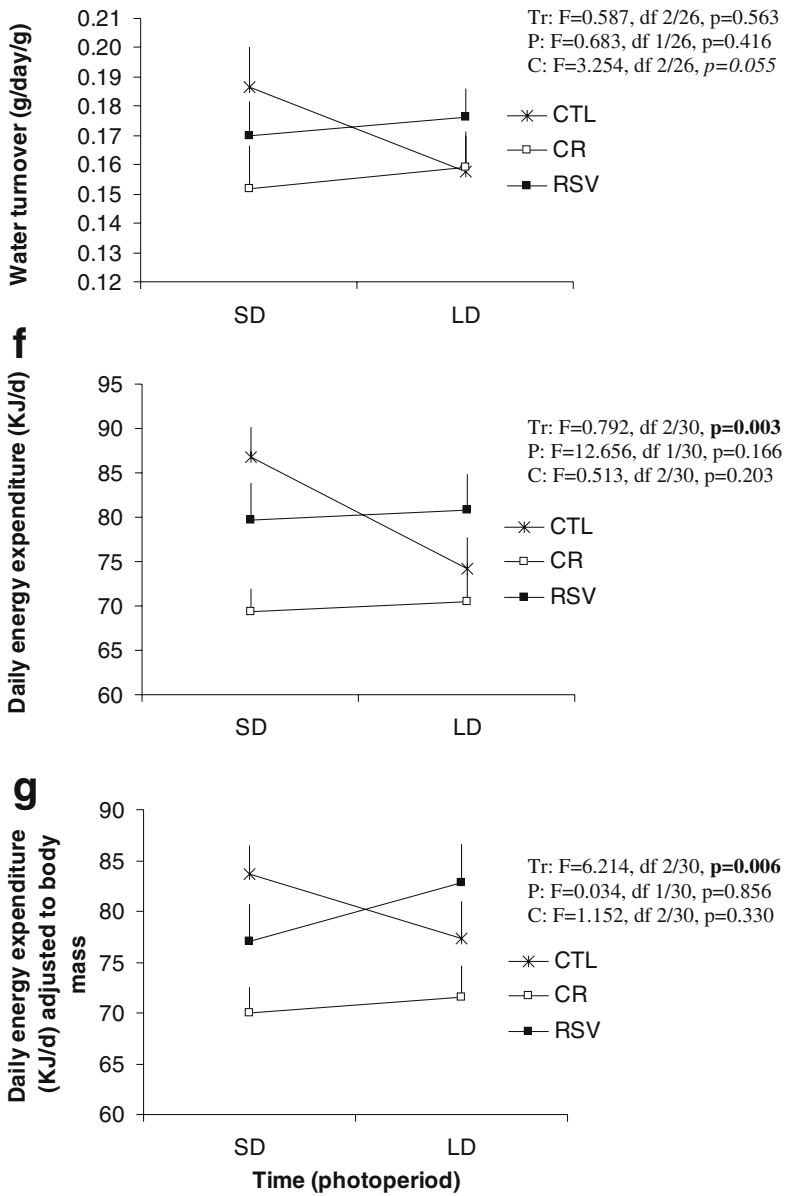

resveratrol $(R S V)$ supplementation compared to control feeding $(\mathrm{CTL})$ in short days $(S D)$ and long days $(L D)$ animals $(n=12$ for each group). $p$ in bold means value is significant and $p$ in italic means value is not significant but shows a slight trend. Values of body mass, fat-free mass and fat mass are expressed in g; values of total body water are expressed in \%; values of water turnover are expressed in g.day ${ }^{-1} \cdot \mathrm{g}^{-1}$ of animal; values of daily energy expenditure are expressed in $\mathrm{kJ} \mathrm{day}^{-1}$. All parameters are expressed as mean \pm SEM

beginning of the LD period and a strong increase in RMR without any increase in spontaneous daily locomotor activity at the end of the LD period. Lastly, although body mass values did not differ between groups during the SD photoperiod, CR animals presented with a significant decrease of their body masses at the end of the LD period. 


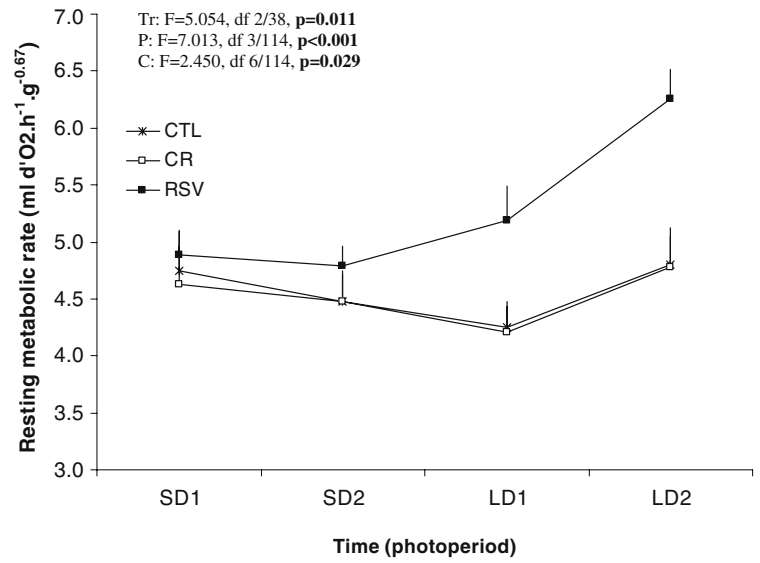

Fig. 4 Effects of photoperiod and treatment on resting metabolic rate. ANOVA results are reported on the graph, for treatment $(T r)$, photoperiod $(P)$ or crossed effects $(C)$ on resting metabolic rate changes during the first year of caloric restriction $(C R)$ or resveratrol (RSV) supplementation compared to control feeding $(\mathrm{CTL})$ in short days $(S D)$ and long days $(L D)$ animals $(n=13$ for CTL group, $n=14$ for CR group, $n=14$ for RSV group). $p$ in bold means value is significant. Values are expressed in $\mathrm{ml} \mathrm{O}_{2} \cdot \mathrm{h}^{-1} \cdot \mathrm{g}^{-0.67}$ as mean \pm SEM

Exposed to a SD photoperiod, mouse lemurs fattened quickly and, after 2-3 months, exhibited a spontaneous reduction of their caloric intake (Génin and Perret 2000). Consequently, CR was proportionally less severe in SD than LD (21\% vs. $30 \%$, respectively). Therefore, the body mass of CR animals did not differ

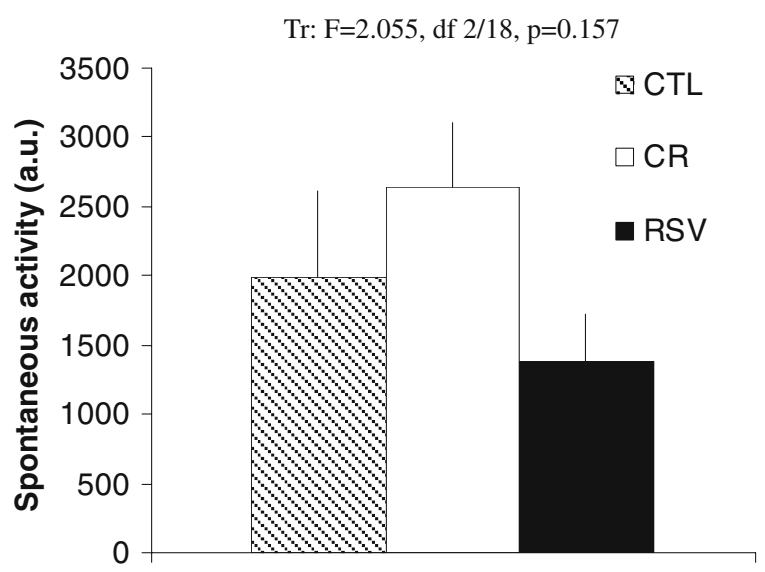

Fig. 5 Effects of treatment on daily spontaneous locomotor activity. ANOVA results are reported on the graph, for treatment $(T r)$ during the first year of caloric restriction $(C R)$ or resveratrol $(R S V)$ supplementation compared to control feeding (CTL) in long days $(L D)$ animals only $(n=5$ for CTL group, $n=9$ for CR group, $n=7$ for RSV group). Values are expressed in a.u. as mean \pm SEM

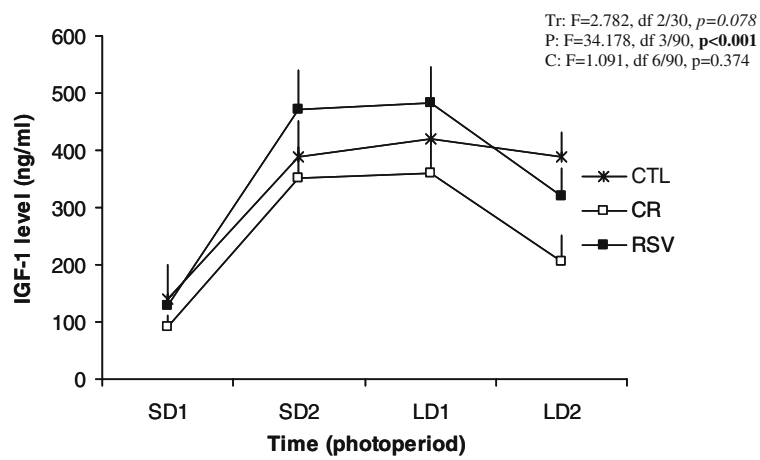

Fig. 6 Effects of photoperiod and treatment on plasma insulinlike growth factor type $1(I G F-1)$ level. Data were logtransformed for statistical analysis. ANOVA results are reported on the right side of the graph, for treatment $(T r)$, photoperiod $(P)$ or crossed effects $(C)$ on IGF-1 level changes during the first year of caloric restriction $(C R)$ or resveratrol $(R S V)$ supplementation compared to control feeding (CTL) in short days $(S D)$ and long days $(L D)$ animals ( $n=11$ for each group). $p$ in bold means value is significant and $p$ in italic means value is not significant but shows a slight trend. Values are expressed in $\mathrm{ng} / \mathrm{ml}$ as mean $\pm \mathrm{SEM}$

from those of controls during the first 6 months of this study i.e. the SD period. Accordingly, IGF-1 levels were not modified. However, at the end of the LD photoperiod, restricted animals exhibited a lower body mass than controls and, although not significantly different, their IGF-1 levels were reduced. A similar decrease in IGF-1 levels has been demonstrated in mice exposed to moderate CR after 24 weeks of treatment (Huffman et al. 2008).

The neuroendocrine system involving $\mathrm{GH}$ and IGF-1 mediates some of the metabolic consequences of caloric excess or restriction (Smith 1996). Obesity is associated with increases in levels of free IGF-1 (Nam et al. 1997) and free fatty acids, both of which are known to decrease GH secretion through a negative feedback mechanism (Lee et al. 1995). Endocrine changes under CR have been extensively studied in rodents (Shimokawa and Higami 2001). Weight loss, as observed with a restricted diet, is accompanied by a decrease in both free fatty acids and free IGF-1 levels, leading to a potential increase in GH secretion (Smith 1996). However, IGF-1 and GH levels were unaffected in humans after a 6 monthperiod of CR (Redman and Ravussin 2009).

Human ageing is marked by a reduction in both GH and IGF-1 concentrations in healthy adults (Veldhuis et al. 2005). Some of the anti-ageing actions of $\mathrm{CR}$ involve the modification of several 


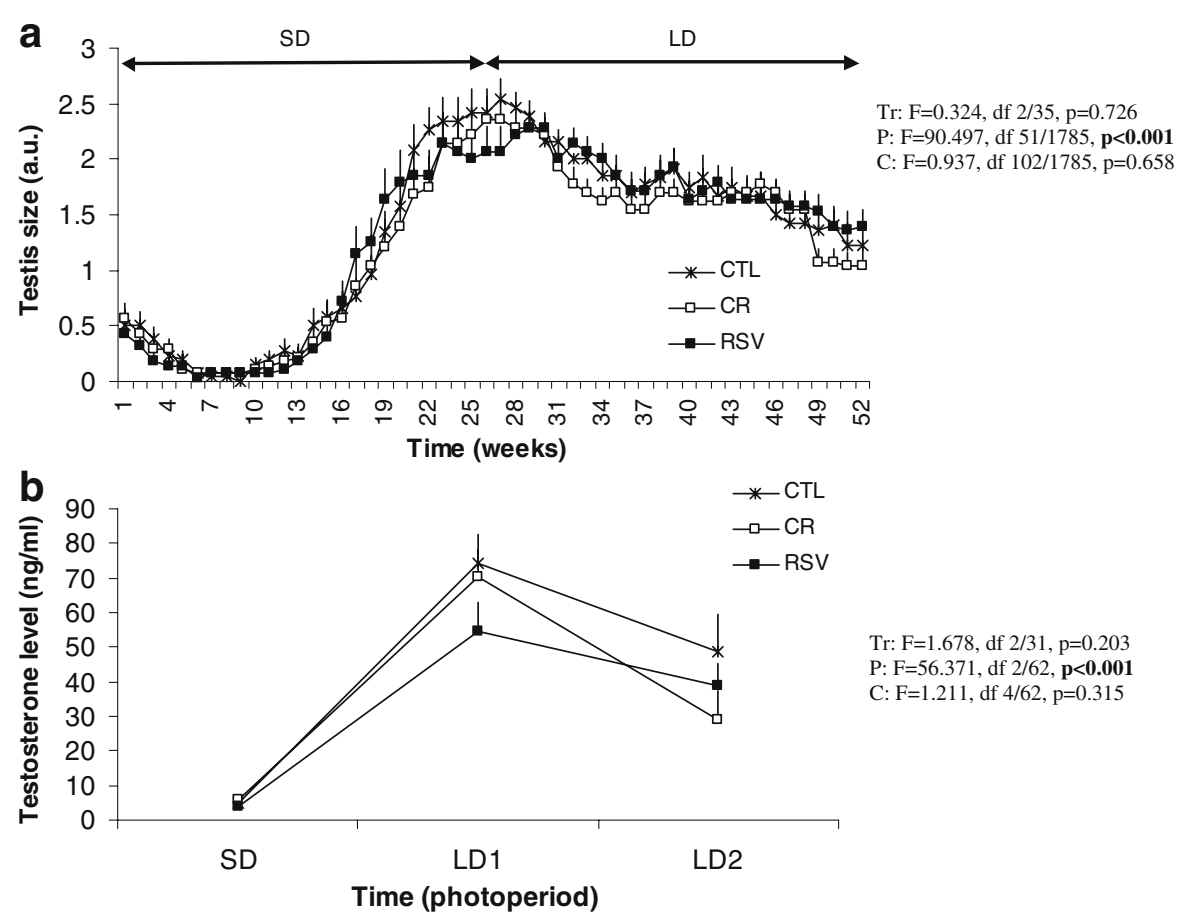

Fig. 7 Effects of photoperiod and treatment on testis size (a) and testosterone level (b). ANOVA results are reported on the right side of the graphs, for treatment $(T r)$, photoperiod $(P)$ or crossed effects $(C)$ on testis size and plasma testosterone level during the first year of caloric restriction $(C R)$ or resveratrol $(R S V)$ supplementation compared to control feeding (CTL) in

neuroendocrine pathways but they remain to be studied (Berner and Stern 2004; Meites 1989). In some mammalian species, CR can reduce the agerelated IGF-1 decline (Berryman et al. 2008). However, the observed decrease in IGF-1 levels after 1 year of $\mathrm{CR}$ in mouse lemurs cannot be attributed to ageing alone. Indeed, in this primate age-related changes in IGF-1 levels are characterised by a progressive decrease during the SD photoperiod, whereas levels remain high during the LD photoperiod even in old age (Terrien et al. 2009a; Aujard et al. 2010). It is most likely that changes in metabolism account for the decrease in IGF-1 in mouse lemurs at the end of the LD period.

Animals under moderate $\mathrm{CR}$ adapted quickly to the protocol. Indeed, body composition as reflected by FM, FFM and TBW was not modified by CR. However, during the SD photoperiod DEE was lower in restricted animals compared with control ones. Similar results were found in rhesus monkeys subjected to a $30 \%$ reduction in caloric intake after several years of treatment (Raman et al. 2007). The short days $(S D)$ and long days $(L D)$ animals $(n=12$ for CTL group, $n=11$ for CR group, $n=11$ for RSV group). $p$ in bold means value is significant. Values of testis size are expressed in a.u. and values of testosterone level are expressed in $\mathrm{ng} / \mathrm{ml}$. Both parameters are expressed as mean \pm SEM

reduction in DEE in the grey mouse lemurs has to be related to its ability to enter daily torpor to conserve energy in the face of environmental constraints (Terrien et al. 2009a). Mouse lemurs exposed to moderate food shortage (Giroud et al. 2008a) exhibited an increasing frequency of daily torpor. Therefore, animals likely minimise energy expenditure and compensate for the effects of CR on body composition by entering deep torpor. Further studies should investigate the length and duration of torpor bouts in CR animals.

RMR, recorded after the daily torpor bout of each animal, was not different between control and CR animals. By contrast, the RMR of human subjects placed under a $25 \%$ CR decreases after three months compared with controls (Martin et al. 2007). In our experiments, the percentage of $\mathrm{CR}$ applied in the mouse lemur might not be sufficient to induce RMR variations or the duration of treatment (1 year) might not be long enough to induce significant modifications. At any rate, this lack of change in RMR also suggests that the animals do not save energy during 
their resting periods but probably during deeper torpor. Moreover, the $\mathrm{CR}$ group presented with lower values of water turnover compared with control animals, indicating greater water retention. This is probably because of the increased frequency of torpor bouts, an important mechanism in this species during SD photoperiods.

From the beginning of the LD photoperiod, all animals lost body mass. Body composition and related body mass did not differ between groups. The LD photoperiod corresponded to the breeding season with a general activation of physiological and behavioural parameters (Perret 1985). In particular, an increase of reproductive functions was expected. As reflected in this study, higher values of testosterone levels were observed for the CTL and $\mathrm{CR}$ groups in the LD period but we noticed no difference between the two groups. Interestingly, the expected increase in LD period-related water turnover was not observed for any group. Moreover, DEE did not differ between control and restricted animals. One possible explanation might be the period when these parameters were measured. Indeed, when the experimental design of this study was established, it was anticipated that animals would exhibit their most significant metabolic changes just after the photoperiodic shifts. However, changes in body mass and DEE as well as IGF-1 levels were more affected by dietary restriction in the second part of the LD period. Therefore, for the remaining years of the study, measurements will be made in the second part of the LD period.

During exposure to the LD photoperiod, CR impacted heavily on body mass variations of grey mouse lemurs (Génin and Perret 2003; Séguy and Perret 2005; Giroud et al. 2008a, b). In the LD photoperiod, mouse lemurs did not use daily torpor to avoid body mass loss even under a $40 \% \mathrm{CR}$ (Giroud et al. 2008a). Moreover, this decrease of body mass could not be explained by changes in RMR or locomotor activity. Contrary to expectations, despite having less energy reserves, no increase in exploratory behaviour, as reflected by spontaneous daily locomotor activity, was observed in CR animals. Similar results were observed after several weeks of $40 \% \mathrm{CR}$ in mouse lemurs in the LD photoperiod (Giroud et al. 2008a). However, when CR was higher, for example $80 \%$ (Génin and Perret 2003), a strong increase in locomotor activity was recorded, suggesting the active search of required food. In the rhesus monkey (Macaca mulatta), an increase in activity levels has been observed for animals under a 30\% CR (Weed et al. 1997). However, these results were only valid for the older male group followed in the NIA study. In monkeys, the literature in this domain was well developed, but the results obtained in the different studies did not allow to conclude about caloric restriction effects on locomotor activity (Kemnitz et al. 1993; Ramsey et al. 1996; Delany et al. 1999; Moscrip et al. 2000). Presently, how CR affects locomotor activity is unclear. As stressed by Ingram et al. (2001), the large variability of the results could be attributed to various factors such as the age and sex of the animals and different CR intensities and durations. Further studies will be necessary to highlight the reality of $\mathrm{CR}$ effects on the locomotor activity of primates.

Animals supplemented with RSV ate approximately the same amount of food as controls during both photoperiods and exhibited similar photoperiodic variations in their body mass and FM. In the SD photoperiod, their body composition, energy expenditure, RMR and hormonal level were similar to those recorded in the control group. Interestingly, the RSV group did not present any difference in body mass compared with the control group, suggesting that RSV does not mimic CR for this parameter, at least after a year of treatment.

However, the FFM of the RSV group was higher in LD period compared with the control group, with a high inter-individual variability. Animals might have developed a larger muscle mass as demonstrated in RSV-supplemented mice that displayed increased muscle strength in locomotor tests after several weeks of treatment (Baur et al. 2006; Lagouge et al. 2006). Moreover, RSV can stimulate in vivo muscle cell glucose uptake through sirtuins and AMPK (Breen et al. 2008), an effect possibly involved in the muscle mass increase of RSV-supplemented mouse lemurs. DEE was also modified by RSV treatment in mouse lemurs with higher values compared with controls at the beginning of the LD period. A similar trend was observed for water turnover. Lastly, contrary to the CR group, the RMR of RSV-supplemented animals was noticeably increased in the early and late stages of the LD period. This RSV effect on the RMR was already seen in a previous study where a 4-week 
supplementation with RSV was sufficient to induce an increase of the grey mouse lemurs' RMR (Dal-Pan et al. 2010). Moreover, as for high-fat mice after several weeks of RSV supplementation (Lagouge et al. 2006), RSV seemed to activate significant energy metabolism of grey mouse lemurs, in particular their RMR.

In summary, a moderate $\mathrm{CR}$ or a mimetic compound supplementation was safely initiated in an adult heterothermic primate. First-year results of the study suggest a good adaptation of the animals to their diet. Preliminary results after 1 year of treatment suggest that RSV produces an activation of energy metabolism without body mass loss in contrast to $\mathrm{CR}$, which produces a decrease of energy expenditure. Taken together, the effects of $\mathrm{CR}$ or RSV supplementation in grey mouse lemurs seemed more important during LD than during SD periods. Physiological and behavioural parameters are highly photoperiod-dependent in this primate, and it is likely that during LD photoperiods energy constraints are more important than during SD photoperiods, thereby leading to a more pronounced effect of the diet treatment. However, changes observed at the end of the LD period might also reflect the chronic effects of treatment after 1 year. The respective roles of this photoperiodic dependency and duration of treatment should be resolved in forthcoming years along with the evolution of validated biomarkers of ageing.

In conclusion, after only 1 year of treatment, it cannot be proposed that the hormesis theory is the most appropriate hypothesis to explain the effects observed in a non-human primate exposed to CR or RSV supplementation. CR and RSV might be two different stressors taking a different path to produce the same effects. Indeed, several differences were observed between CR and RSV supplementation, questioning the similarity of the pathways involved. If similar pathways between CR and RSV supplementation exist, as for example through sirtuins (especially SIRT1), it will be necessary to investigate the evolution of the levels of such molecules in future years of the RESTRIKAL project.

Acknowledgments The authors acknowledge the continuing assistance provided by Eric Gueton for daily feeding and care provided to animals. Laurine Haro is recognised for expert technical assistance. This work was carried out with the financial support of the French National Research Agency (project ANR-06-PNRA-010-01) and the Foundation for French Medical Research.

Open Access This article is distributed under the terms of the Creative Commons Attribution Noncommercial License which permits any noncommercial use, distribution, and reproduction in any medium, provided the original author(s) and source are credited.

\section{References}

Allard JS, Perez E, Zou S, de Cabo R (2009) Dietary activators of Sirt1. Mol Cell Endocrinol 299(1):58-63

Anderson RM, Bitterman KJ, Wood JG, Medvedik O, Sinclair DA (2003) Nicotinamide and PNC1 govern lifespan extension by calorie restriction in Saccharomyces cerevisiae. Nature 423(6936):181-185

Anderson R, Prolla T (2009) PGC-1[alpha] in ageing and antiageing interventions. Biochim Biophys Acta 1790 (10):1059-1066

Athar M, Back JH, Tang X, Kim KH, Kopelovich L, Bickers DR, Kim AL (2007) Resveratrol: a review of preclinical studies for human cancer prevention. Toxicol Appl Pharmacol 224(3):274-283

Aujard F, Perret M (1998) Age-related effects on reproductive function and sexual competition in the male prosimian primate, Microcebus murinus. Physiol Behav 64(4):513-519

Aujard F, Dkhissi-Benyahya O, Fournier I, Claustrat B, Schilling A, Cooper HM, Perret M (2001) Artificially accelerated ageing by shortened photoperiod alters early gene expression (Fos) in the suprachiasmatic nucleus and sulfatoxymelatonin excretion in a small primate, Microcebus murinus. Neurosci 105(2):403-412

Aujard F, Cayetanot F, Terrien J, Van Someren EJW (2007) Attenuated effect of increased daylength on activity rhythm in the old mouse lemur, a non-human primate. Exp Gerontol 42(11):1079-1087

Aujard F, Bluet-Pajot MT, Zizzari P, Perret M, Epelbaum J (2010) Plasma IGF-1 level is a marker of individual life-span in a primate, the gray mouse lemur. Ageing Research 2:e1

Barger JL, Kayo T, Vann JM, Arias EB, Wang J, Hacker TA, Wang Y, Raederstorff D, Morrow JD, Leeuwenburgh C, Allison DB, Saupe KW, Cartee GD, Weindruch R, Prolla TA (2008) A low dose of dietary resveratrol partially mimics caloric restriction and retards aging parameters in mice. PLoS One 3(6):e2264

Baur JA, Pearson KJ, Price NL, Jamieson HA, Lerin C, Kalra A, Prabhu VV, Allard JS, Lopez-Lluch G, Lewis K, Pistell PJ, Poosala S, Becker KG, Boss O, Gwinn D, Wang MY, Ramaswamy S, Fishbein KW, Spencer RG, Lakatta EG, Le Couteur D, Shaw RJ, Navas P, Puigserver P, Ingram DK, de Cabo R, Sinclair DA (2006) Resveratrol improves health and survival of mice on a high-calorie diet. Nature 444(7117):337-342

Baur JA (2010) Resveratrol, sirtuins, and the promise of a DR mimetic. Mech Ageing Dev 131(4):261-169

Berner YN, Stern F (2004) Energy restriction controls aging through neuroendocrine signal transduction. Ageing Res Rev 3(2):189-198 
Berryman DE, Christiansen JS, Johannsson G, Thorner MO, Kopchick JJ (2008) Role of the GH/IGF-1 axis in lifespan and healthspan: lessons from animal models. Growth Horm IGF Res 18(6):455-471

Blanc S, Geloen A, Pachiaudi C, Gharib C, Normand S (2000) Validation of the doubly labelled water method in rats during isolation and simulated weightlessness. Am J Physiol Regul Integr Comp Physiol 279(6): R1964-R1979

Blanc S, Schoeller D, Kemnitz J, Weindruch R, Colman R, Newton W, Wink K, Baum S, Ramsey J (2003) Energy expenditure of rhesus monkeys subjected to 11 years of dietary restriction. J Clin Endocrinol Metab 88(1):16-23

Blanc S, Colman R, Kemnitz J, Weindruch R, Baum S, Ramsey J, Schoeller D (2005) Assessment of nutritional status in rhesus monkeys: comparison of dual-energy X-ray absorptiometry and stable isotope dilution. J Med Primatol 34 (3):130-138

Bordone L, Guarente L (2005) Calorie restriction, SIRT1 and metabolism: understanding longevity. Nature Rev Mol Cell Biol 6(4):298-305

Borra MT, Smith BC, Denu JM (2005) Mechanism of human SIRT1 activation by resveratrol. J Biol Chem 280 (17):17187-17195

Breen DM, Sanli T, Giacca A, Tsiani E (2008) Stimulation of muscle cell glucose uptake by resveratrol through sirtuins and AMPK. Biochem Biophys Res Commun 374(1): $117-122$

Campbell BA, Richardson R (1988) Effect of chronic undernutrition on susceptibility to cold stress in young adult and aged rats. Mech Ageing Dev 44:193-202

Canto C, Gerhart-Hines Z, Feige JN, Lagouge M, Noriega L, Milne JC, Elliott PJ, Puigserver P, Auwerx J (2009) AMPK regulates energy expenditure by modulating NAD+ metabolism and SIRT1 activity. Nature 458(7241): $1056-1060$

Cayetanot F, Van Someren EJW, Perret M, Aujard F (2005) Shortened seasonal photoperiodic cycles accelerate aging of the diurnal and circadian locomotor activity rhythms in a primate. J Biol Rhythms 20(5):461-469

Chen D, Guarente L (2007) SIR2: a potential target for calorie restriction mimetics. Trends Mol Med 13(2):64-71

Cohen HY, Miller C, Bitterman KJ, Wall NR, Hekking B, Kessler B, Howitz KT, Gorospe M, de Cabo R, Sinclair DA (2004) Calorie restriction promotes mammalian cell survival by inducing the SIRT1 deacetylase. Science 305 (5682):390-392

Colman RJ, Anderson RM, Johnson SC, Kastman EK, Kosmatka KJ, Beasley TM, Allison DB, Cruzen C, Simmons HA, Kemnitz JW, Weindruch R (2009) Caloric restriction delays disease onset and mortality in rhesus monkeys. Science 325:201-204

Coward WA (1990) Calculation of pool sizes and flux rates. In: Prentice AM (ed) The doubly labelled water method: technical recommendations for use in humans. Report of an IDECG Expert Working Group, AERA, Vienna, Austria, Chapter 4

Dal-Pan A, Blanc S, Aujard F (2010) Resveratrol suppresses body mass gain in a seasonal non-human primate model of obesity. BMC Physiol (in press)
Dasgupta B, Milbrandt J (2007) Resveratrol stimulates AMP kinase activity in neurons. Proc Natl Acad Sci U S A 104 (17):7217-7222

Delany JP, Hansen BC, Bodkin NL, Hannah J, Bray GA, Leibel RL (1999) Long-term calorie restriction reduces energy expenditure in aging monkeys. J Gerontol A Biol Sci Med Sci 54:B5-B11

de Oliveira SL, Diniz DB, Amaya-Farfan J (2003) Carbohydrateenergy restriction may protect the rat brain against oxidative damage and improve physical performance. Br J Nutr 89:89-96

Dhenain M, Chenu E, Hisley CK, Aujard F, Volk A (2003) Regional atrophy in the brain of lissencephalic mouse lemur primates: measurement by automatic histogram-based segmentation of MR images. Magn Reson Med 50(5):984-992

Donnelly LE, Newton R, Kennedy GE, Fenwick PS, Leung RHF, Ito K, Russell REK, Barnes PJ (2004) Antiinflammatory effects of resveratrol in lung epithelial cells: molecular mechanisms. Am J Physiol Lung Cell Mol Physiol 287(4):L774-L783

Dubey A, Forster MJ, Lal H, Sohal RS (1996) Effect of age and caloric intake on protein oxidation in different brain regions and on behavioral functions of the mouse. Arch Biochem Biophys 333:189-197

Gardner EM (2005) Caloric restriction decreases survival of aged mice in response to primary influenza infection. $\mathrm{J}$ Gerontol A Biol Sci Med Sci 60(6):688-694

Génin F, Perret M (2000) Photoperiod-induced changes in energy balance in gray mouse lemurs. Physiol Behav 71 (3-4):315-321

Génin F, Perret M (2003) Daily hypothermia in captive grey mouse lemurs (Microcebus murinus): effects of photoperiod and food restriction. Comp Biochem Physiol B 136(1):71-81

Gilbert C, Blanc S, Giroud S, Trabalon M, Le Maho Y, Perret M, Ancel A (2007) Role of huddling on the energetic of growth in a newborn altricial mammal. Am J Physiol Regul Integr Comp Physiol 293(2):R867-R876

Giroud S, Blanc S, Aujard F, Bertrand F, Gilbert C, Perret M (2008a) Chronic food shortage and seasonal modulations of daily torpor and locomotor activity in the grey mouse lemur (Microcebus murinus). Am J Physiol Regul Integr Comp Physiol 294:R1958-R1967

Giroud S, Perret M, Le Maho Y, Momken I, Gilbert C, Blanc S (2008b) Gut hormones in relation to body mass and torpor pattern changes during food restriction and re-feeding in the grey mouse lemur. J Comp Physiol B 179(1):99-111

Giroud S, Perret M, Stein P, Goudable J, Aujard F, Gilbert C, Robin JP, Le Maho Y, Zahariev A, Blanc S, Momken I (2010) The grey mouse lemur uses season-dependent fat or protein sparing strategies to face chronic food restriction. PLoS One 5(1):e8823

Gredilla P, Sanz A, Lopez-Torres M, Barja G (2001) Caloric restriction decreases mitochondrial generation at complex 1 and lowers oxidative damage. FASEB J 15:1589-1591

Heilbronn LK, de Jonge L, Frisard MI, DeLany JP, LarsonMeyer DE, Rood J, Nguyen T, Martin CK, Volaufova J, Most MM, Greenway FL, Smith SR, Deutsch WA, Williamson DA, Ravussin E (2006) Effect of 6-month calorie restriction on biomarkers of longevity, metabolic 
adaptation, and oxidative stress in overweight individuals: a randomized controlled trial. J Am Med Assoc 295 (21):2482-2482

Howitz KT, Bitterman KJ, Cohen HY, Lamming DW, Lavu S, Wood JG, Zipkin RE, Chung P, Kisielewski A, Zhang LL, Scherer B, Sinclair DA (2003) Small molecule activators of sirtuins extend Saccharomyces cerevisiae lifespan. Nature 425(6954):191-196

Huffman DM, Moellering DR, Grizzle WE, Stockard CR, Johnson MS, Nagy TR (2008) Effect of exercise and calorie restriction on biomarkers of aging in mice. Am J Physiol Regul Integr Comp Physiol 294(5):R1618-R1627

Iannelli P, Zarrilli V, Varricchio E, Tramontano D, Mancini FP (2007) The dietary antioxidant resveratrol affects redox changes of PPAR[alpha] activity. Nutr Metab Cardiovasc Dis 17(4):247-256

Ingram DK, Cutler RG, Weindruch R, Renquist DM, Knapka JJ, April M, Belcher CT, Clark MA, Hatcherson CD, Marriott BM (1990) Dietary restriction and ageing: the initiation of a primate study. J Gerontol 45(5):B148-B163

Ingram DK, Chefer S, Matochik J, Moscrip TD, Weed J, Roth GS, London ED, Lane MA (2001) Aging and caloric restriction in nonhuman primates: behavioral and in vivo brain imaging studies. Ann N Y Acad Sci 928:316-326

Ingram DK, Roth GS, Lane MA, Ottinger MA, Zou S, de Cabo R, Mattison JA (2006) The potential for dietary restriction to increase longevity in humans: extrapolation from monkey studies. Biogerontology 7(3):143-148

Ingram DK, Young J, Mattison JA (2007) Calorie restriction in nonhuman primates: assessing effects on brain and behavioral ageing. Neurosc 145(4):1359-1364

Kemnitz JW, Weindruch R, Roecker EB, Crawford K, Kaufman PL, Ershler WB (1993) Dietary restriction of adult male rhesus monkeys: design, methodology, and preliminary findings from the first year of study. J Gerontol 48(1): B17-B26

Kraska A, Dorieux O, Picq JL, Petit F, Bourrin E, Chenu E, Volk A, Perret M, Hantraye P, Mestre-Frances N, Aujard F, Dhenain M (2009) Age-associated cerebral atrophy in mouse lemur primates. Neurobiol Aging (in press)

Lagouge M, Argmann C, Gerhart-Hines Z, Meziane H, Lerin C, Daussin F, Messadeq N, Milne J, Lambert P, Elliott P, Geny B, Laakso M, Puigserver P, Auwerx J (2006) Resveratrol improves mitochondrial function and protects against metabolic disease by activating SIRT1 and PGC-1 [alpha]. Cell 127(6):1109-1122

Lane MA, Ingram DK, Cutler RG, Knapka JJ, Barnard DE, Roth GS (1992) Dietary restriction in nonhuman primates: progress report on the NIA study. Ann N Y Acad Sci 673:36-45

Lane MA, Tilmont EM, De Angelis H, Handy A, Ingram DK, Kemnitz JW, Roth GS (2000) Short-term calorie restriction improves disease-related markers in older male rhesus monkeys (Macaca mulatta). Mech Ageing Dev 112 (3):185-196

Lane MA, Mattison J, Ingram DK, Roth GS (2002) Caloric restriction and ageing in primates: Relevance to humans and possible CR mimetics. Microsc Res Tech 59(4): 335-338

Lee EJ, Kim KR, Lee HC, Cho JH, Nam MS, Nam SY, Song YD, Lim SK, Huh KB (1995) Acipimox potentiates growth hormone response to growth hormone releasing hormone by decreasing serum free fatty acid levels in hyperthyroidism. Metabolism 44(11):1509-1512

Lee CK, Klopp RG, Weindruch R, Prolla TA (1999) Gene expression profile of aging and its retardation by caloric restriction. Science 285:1390-1393

Lin SJ, Defossez PA, Guarente L (2000) Requirement of NAD and Sir2 for life-span extension by caloric restriction in Saccharomyces cerevisiae. Science 289:2126-2128

Martin B, Pearson M, Kebejian L, Golden E, Keselman A, Bender M, Carlson O, Egan J, Ladenheim B, Cadet JL, Becker KG, Wood W, Duffy K, Vinayakumar P, Maudsley S, Mattson MP (2007) Sex-dependent metabolic, neuroendocrine, and cognitive responses to dietary energy restriction and excess. Endocrinology 148(9):4318-4333

Masoro EJ (2006) Role of hormesis in life extension by caloric restriction. Dose Response 5(2):163-173

McCay CM, Crowell MF, Maynard LA (1935) The effect of retarded growth upon the length of life span and upon the ultimate body size. J Nutr 10(1):63-79

Meites J (1989) Evidence that underfeeding acts via the neuroendocrine system to influence ageing processes. Prog Clin Biol Res 287:169-180

Mokdad AH, Marks JS, Stroup DF, Gerberding JL (2004) Actual causes of death in the United States. J Am Med Assoc 291(10):1238-1245

Moscrip TD, Ingram DK, Lane MA, Roth GS, Weed JL (2000) Locomotor activity in female rhesus monkeys: assessment of age and calorie restriction effects. J Gerontol A Biol Sci Med Sci 55(8):B373-B380

Nam SY, Lee EJ, Kim KR, Cha BS, Song YD, Lim SK, Lee HC, Huh KB (1997) Effect of obesity on total and free insulin-like growth factor (IGF)-1, and their relationship to IGF-binding protein (BP)-1, IGFBP-2, IGFBP-3, insulin, and growth hormone. Int J Obes 21:355-359

Nemoz-Bertholet F, Menaker M, Aujard F (2004) Are agerelated deficits in balance performance mediated by time of day in a prosimian primate (Microcebus murinus)? Exp Gerontol 39(5):841-848

Pearson KJ, Baur JA, Lewis KN, Peshkin L, Price NL, Labinskyy N, Swindell WR, Kamara D, Minor RK, Perez E, Jamieson HA, Zhang Y, Dunn SR, Sharma K, Pleshko N, Woollett LA, Csiszar A, Ikeno Y, Le Couteur D, Elliott PJ, Becker KG, Navas P, Ingram DK, Wolf NS, Ungvari Z, Sinclair DA, de Cabo R (2008) Resveratrol delays age-related deterioration and mimics transcriptional aspects of dietary restriction without extending life span. Cell Metab 8(2):157-168

Perret M (1985) Diurnal variations in plasma testosterone concentrations in the male lesser mouse lemur (Microcebus murinus). J Reprod Fertil 74(1):205-213

Perret M, Aujard F (2001) Daily hypothermia and torpor in a tropical primate: synchronization by 24 -h light-dark cycle. Am J Physiol Regul Integr Comp Physiol 281(6):R1925-1933

Perret M, Aujard F (2005) Ageing and season affect plasma dehydroepiandrosterone sulfate (DHEA-S) levels in a primate. Exp Gerontol 40(7):582-587

Picard F, Kurtev M, Chung N, Topark-Ngarm A, Senawong T, Machado de Oliveira R, Leid M, McBurney MW, Guarente L (2004) Sirt1 promotes fat mobilization in white adipocytes by repressing PPAR-[gamma]. Nature 429(6993):771-776 
Picq JL (2007) Ageing affects executive functions and memory in mouse lemur primates. Exp Gerontol 42(3):223-232

Racette SB, Schoeller DA, Luke AH, Shay K, Hnilicka J, Kushner RF (1994) Relative dilution spaces of $2 \mathrm{H}$ and 18 O-labelled water in humans. Am J Physiol Endocrinol Metab 30:E585-E590

Raman A, Ramsey JJ, Kemnitz JW, Baum ST, Newton W, Colman RJ, Weindruch R, Beasley MT, Schoeller DA (2007) Influences of calorie restriction and age on energy expenditure in the rhesus monkey. Am J Physiol Endocrinol Metab 292:E101-E106

Ramsey JJ, Roecker EB, Weindruch R, Baum ST, Kemnitz JW (1996) Thermogenesis of adult male rhesus monkeys: results through 66 months of dietary restriction. FASEB J 10:A726

Rattan SIS (2004) Aging, anti-aging, and hormesis. Mech Ageing Dev 125:285-287

Redman LM, Ravussin E (2009) Endocrine alterations in response to calorie restriction in humans. Mol Cell Endocrinol 299(1):129-136

Rodgers JT, Lerin C, Haas W, Gygi SP, Spiegelman BM, Puigserver P (2005) Nutrient control of glucose homeostasis through a complex of PGC-1 [alpha] and SIRT1. Nature 434 (7029):113-118

Séguy M, Perret M (2005) Factors affecting the daily rhythm of body temperature of captive mouse lemurs (Microcebus murinus). J Comp Physiol B 175(2):107-115

Shanmuganayagam D, Warner TF, Krueger CG, Reed JD, Folts JD (2007) Concord grape juice attenuates platelet aggregation, serum cholesterol and development of atheroma in hypercholesterolemic rabbits. Atherosclerosis 190(1):135-142

Shimokawa I, Higami Y (2001) Leptin and anti-ageing action of caloric restriction. J Nutr Health Ageing 5:43-48

Smith SR (1996) The Endocrinology of Obesity. In: Bray G (ed) Endocrinology and Metabolism Clinics of North America. WB Saunders, Philadelphia, pp 921-942

Sohal RS, Agarwal S, Candas M, Forster MJ, Lal H (1994) Effect of age and caloric restriction on DNA oxidative damage in different tissues of C57BL/6 mice. Mech Ageing Dev 76:215-224

Suh Y, Atzmon G, Cho MO, Hwang D, Liu B, Leahy DJ, Barzilai N, Cohen P (2008) Functionally significant insulin-like growth factor I receptor mutations in centenarians. Proc Nat Acad Sci USA 105(9):3438-3442
Terrien J, Zizzari P, Epelbaum J, Perret M, Aujard F (2009a) Daily rhythms of core temperature and locomotor activity indicate different adaptive strategies to cold exposure in adult and aged mouse lemurs acclimated to a summer-like photoperiod. Chronobiol Int 26(5):838-853

Terrien J, Zahariev A, Blanc S, Aujard F (2009b) Impaired control of body cooling during heterothermia represents the major energetic constraint in an aging non-human primate exposed to cold. PLoS One 4(10):e7587, 1-9

Tissenbaum HA, Guarente L (2001) Increased dosage of a sir-2 gene extends lifespan in Caenorhabditis elegans. Nature 410:227-230

Valenzano DR, Terzibasi E, Genade T, Cattaneo A, Domenici L, Cellerino A (2006) Resveratrol prolongs lifespan and retards the onset of age-related markers in a short-lived vertebrate. Current Biol 16(3):296-300

Veldhuis JD, Erickson D, Iranmanesh A, Miles JM, Bowers CY (2005) Sex-steroid control of the ageing somatotropic axis. Endocrinol Metab Clin North Am 34:877-893, viii

Wakeling L, Ions L, Ford D (2009) Could Sirt1-mediated epigenetic effects contribute to the longevity response to dietary restriction and be mimicked by other dietary interventions? AGE 31(4):327-341

Weed JL, Lane MA, Roth GS, Speer DL, Ingram DK (1997) Activity measures in rhesus monkeys on long-term calorie restriction. Physiol Behav 62(1):97-103

Weindruch R, Keenan KP, Carney JM, Fernandes G, Feuers RJ, Floyd RA, Halter JB, Ramsey JJ, Richardson A, Roth GS, Spindler SR (2001) Caloric restriction mimetics: metabolic interventions. J Gerontol A Biol Sci Med Sci 56(1):20-33

Weir JB (1949) New methods for calculating metabolic rate with special reference to protein metabolism. J Physiol 109:1-9

Witte AV, Fobker M, Gellner R, Knecht S, Flöel A (2009) Caloric restriction improves memory in elderly humans. Proc Nat Acad Sci USA 106(4):1255-1260

Wood JG, Rogina B, Lavu S, Howitz K, Helfand SL, Tatar M, Sinclair D (2004) Sirtuin activators mimic caloric restriction and delay ageing in metazoans. Nature 430(7000): 686-689

Zainal TA, Oberley TD, Allison DB, Szweda LI, Weindruch R (2000) Caloric restriction of rhesus monkeys lowers oxidative damage in skeletal muscle. FASEB J 14:1825-1836 